\title{
Applied linguistics - a science of culture?
}

\author{
Gertraud Benke (Wien)
}

\begin{abstract}
In this article, the status of applied linguistics as discipline is questioned and problems of establishing it - and other newly formed scientific enterprises like cultural science - as disciplines are discussed. This discussion is contextualized using the author's own experience as applied linguist working in (the institutional structure of) Austria. Secondly, applied linguistics is presented as complementing cultural science, with both exploring at times the same phenomena albeit under different perspectives and focussing on different levels of experience. Two examples of research involving such a joint interest with different foci are discussed.
\end{abstract}

Applied linguistics - a science of culture? When I was invited to consider this question, I first wondered - what exactly is "cultural science", how would one define its core and periphery, its limits such as to decide whether applied linguistics is within or out of its scope? Yet, before I started to tackle this question in earnest, I realized that even if I were to answer all these questions to ones satisfaction, I would still need to address the very same issues for applied linguistics itself. Talking from the inside of applied linguistics, this seemed an even more difficult task - and it is this issue, I will deal with on a theoretical level in the first part of my paper. The second part will be devoted to a short discussion of what applied linguistics can offer to cultural science, followed by a discussion of two examples of how applied linguistics informs or contributes to cultural science. In all these, I do not claim an impartial, objective point of view on applied linguistics (or cultural science). Drawing on my own life experience as an applied linguist in Vienna, I will present a reasoned account of what applied linguistics looks like from my vantage point - given the institutional context it is operating in (in Vienna, Austria and beyond).

\section{$1 \quad$ Applied linguistics - a discipline?}

What is "applied linguistics"? When talking this over with a friend, who is doing "feminist linguistics", she astounded me saying that she did not consider herself an "applied linguist" while I had put her firmly within. The linguistics department of Vienna offers an M.A. in "applied linguistics", and there is a full professor position devoted to "applied linguistics" with a number of assistant professorships coming along. First year students of linguistics - yet not specialized in any field - have to participate in a special lecture "introduction to applied linguistics", which is held by about ten experts said to be engaged in various fields of applied 
linguistics, each of them presenting their field of expertise. Treating this as an instance of a complex speech act of definition, applied linguistics includes the fields of psycholinguistics, first and second language acquisition, text comprehension, conversation analysis, political discourse analysis, gender and language, language policies, neuro-linguistics, media language etc. These heterogeneous topics operate on different levels - some define social areas of application or study (media, gender etc.), some address methods of analysis (conversation analysis), some the intersection of two established disciplines (psycholinguistics), and some theoretized linguistic objects (text, discourse). Even more confusing is the fact that not all these areas are offered as tracks of the "applied linguistics department" or are at least being taught by faculty therein, but that many of these (sub)fields are in fact being taught by faculty of the "general linguistics" department, and many ongoing research projects e.g. in first language acquisition are done by people from the latter department.

So what do people in the "applied linguistics" department (in Vienna) do, and why is so much "applied linguistics" done by "general linguists"? While these institutional facts may seem baffling, in fact there is a very clear logic behind them. Faculty and research in applied linguistics in Vienna has for a long time been engaged in investigating language use - the discursive configuration of enactment, re-enactment and creation of social configurations within particular social systems. Research projects included but were not restricted to doctorpatient communication (Lalouschek, Menz, Wodak 1990), legal discourse (Pfeiffer, Strohal, Wodak 1987), prejudice, i.e. anti-Semitism (Wodak et al. 1990) and racism in discourse (Matouschek, Wodak, Januschek, 1995; Reisigl, Wodak 2000), the construction of national identity (Wodak et al. 1998), decision making processes in schools (Wodak et al. 1991) and in EU organizations, language policy, and organizational discourse (Wodak, 2001). All these areas of study share certain core assumptions: (i) language (use) shapes and is shaped by the social setting, the institution or social context with its power structure which is enacted through language/discourse. (ii) One strives (among others) to describe and understand the interplay between a specific language game and a particular social structure. Thus (iii) one uses political, historical and sociological theories and research to conceptualise the social structure or field. (iv) The methods being applied frequently aim at an understanding on or above the utterance/clause/turn level. A driving metaphor for language (use) is some variant of speech act theory with the implication of the constituting nature of utterances, the later realization of the co-construction of meaning (Clark, Wilkes-Gibbs, 1992; Sperber, Wilson, 1995), the idea of multiple (even concurrent) meanings (as in indirect speech acts), the conscious or unconscious realization of social or personal intentions.

In contrast, "applied linguistics" done in the general linguistics department draws on a completely different set of underlying principles. While in the former research program, the interplay of language use and construction of meaning/reality is central, in this program the focus stays with language and the human language faculty (e.g. Klampfer, Vollmann, Dressler, 2000). For the most part, theories evolve around an individual language learner and their (linguistic) developmental trajectories, that is psychological or neuro-biological models of the working of the language (acquisition) device. And as in the disciplines introduced by 
hyphenation, the underlying research model is still strongly cognitive and positivistic. Methods of "proof" appeal to statistical evidence of counted occurrences (e.g. in first language acquisition), or measures of brain scans while performing bilingual tasks. Alternatively, one tries to formulate a cognitive processing model, which fits observed errors and correct performances.

While I think it does make sense to set these areas of research off from each other, their institutional affiliations run counter to the implicit definition provided by the "introduction to applied linguistics" lecture.

If we turn from the local (Austrian) context, to the use of the term "applied linguistics" in general, the picture is no less confusing. If one searches for German language publications containing the keywords "Angewandte Linguistik" (applied linguistics) the results are meagre. Almost all of the few titles I found in a library search of the library of the University of Vienna are in one way or other related to GAL, the German association for applied linguistics (e.g. its publication series in the Lang publishing house, or proceedings from GAL sponsored conferences etc.). Especially telling is the lack of literature titled "Introduction to Applied Linguistics" (that is "Einführung in die Angewandte Sprachwissenschaft"). What does this tell us? I think the lack of publications that announce their affiliation to applied linguistics in their title is due to the fact that most of the possible authors feel more devoted to some of the subfields noted above than to this abstract complex of 'applied linguistics'. Instead of introductions to applied linguistics, we find introductions to text linguistics, discourse analysis, psycholinguistics, etc.

If we turn to the international (English speaking) context, applied linguistics has long been co-referential with second language acquisition research, and as far as the US is concerned it is still predominantly defined by it (as one can see from the program of the annual conference of the American Association for Applied Linguistics, i.e. AAAL). Thus it is not surprising that driving theoretical frameworks and contributions to (a certain framework of) "applied linguistics" come from people with institutional affiliations outside of linguistics - such as (micro-)sociology (Schegloff 1991, Sacks 1995, Gumperz 1982), linguistic anthropology (Ochs, Gonzales, Jacoby, 1993), psychology (McKoon, Ratcliff, 1992, Crawford 1995). Likewise, in the UK, people are coming from media studies (Kress, van Leeuwen 1996), education (Kress), and psychology (Wilkinson, Kitzinger 1995) to name a few.

It is this latter strand of applied linguistics, the (kind of) applied linguistics also being the main research focus of the department of applied linguistics in Vienna, I will be concerned with in the following sections of this article.

If we step back from the historical and institutional facts, which led to this peculiar situation of important work in applied linguistics being done by people with other affiliations, we may start to wonder about the institutional organisation of research and the sciences, which provides the context for this development. As it stands, applied linguistics is by no means the only "white raven" in the circus of the higher education system. Alongside "applied linguistics", we saw the emergence of cognitive science, neuro-sciences, gender studies and 
cultural studies to name a few in the last three decades. All of these share an important characteristic: they transcend the boundaries of one clearly defined discipline, they assemble around a common theme, a shared phenomenon of investigation. At least initially, the topic was (or is) either outside the boundaries of one of the established disciplines (like "the mind", which was then outside the boundaries of psychology in the behaviourist mainstream), or it is treated as a "fuzzy concept", which is first approached as something we know through our folk theories, and which is in need of a better understanding. In this process, the disciplinary frameworks are seen as insufficient or simply beside the point (gender studies). Consequently, all of these also share the problem posed by the institutional organization of knowledge. Research money, grants, professorships, assistantships are bound up in the institutional system with its historically grown structure. Thus, one has only two options to get a share of the cake to do these kinds of "new research" outside the established traditions: either one has to affiliate oneself (the new field) to one of the established traditions (e.g. cognitive science is mostly affiliated with psychology as are the neuro-sciences), or one has to establish the field as a new discipline with its own institutional structure (e.g. gender research, theory of science). Both strategies are naturally raising opposition from those who are most concerned about the consequent shift of balance of power and resources.

As the name implies, applied linguistics is affiliated with "linguistics", even though many important contributions come from people nominally working in other disciplines. Was this then the stroke of a genius - or madman, who managed to sell "our business" to linguists? Is there a unity beyond the name?

One common theme of linguists is the interest in language, its function, its design, its enactment. Applied linguists are frequently interested in the language "above the clause level", in texts, in discourse, in conversation. The key issue to determine the unity of the field seems to be the definition of the driving question(s) put to language. Coming from structuralism, the old (formal) question was concerned with the design of language - which form is used for which function (and how are the units been put together), using a two-tiered conception of the signification process which was frequently attributed to Saussure (1967). Many applied linguists are still interested in the structural aspects of language and its social signification, e.g. when studying the function of the phrase "how do you do" in doctor-patient communication (Coupland, Robinson, Coupland, 1994); or studies on the meaning of different particles in verbal exchanges (Schiffrin, 1987), or the meaning of repetition (Tannen, 1989). Yet, applied linguistics does not stop here. Shifting the ontological and epistemological position with regard to reality and meaning in discourse, applied linguists address the question of how language constructs a particular reality or is intentionally used in the construction of the world. In this perspective, language can no longer just "reflect" or "be other part" of a given meaning, the meanings are constructed, changed, modified by language, they are dynamic objects. Language makes reality at a particular time, at a particular place, with a particular meaning. This conception of language no longer squares up with the formfunction conception used in the studies of the language learner, i.e. the study of the language faculty. In this conception of language, language is no longer seen static, but constructed, 
dynamic, shifting. The perspective is not one from a person put inside a language community, facing a stable object to internalise, but from a person seemingly outside, studying language communities and their struggles of definition, change, and existence. Where general linguistics constructs the language system, applied linguistics deconstructs the stability of this system and demonstrates its fragility and fleeing nature.

Thus, this applied linguistics dissolves the system being constructed - but doing so, it works from the same framework as general linguists. When looking at variation in language, in meaning, in the signification system, applied linguists make use of the instruments developed by formal linguists. The code used by a particular social (sub)group, the struggles for power enacted in language can still be studied as structured objects following the principles developed in general linguistics.

Moreover, applied linguists are frequently encultured in their scientific community studying the foundations of formal linguistics (phonetics, phonology, morphology, syntax and semantics) before they come to study (or specialize in) applied linguistics. Thus, the first model of language will often be the one used to conceptualise language acquisition, i.e. the individual language learner and the structure she has to master. When in the course of their individual educational life histories, applied linguists start to turn away from this model of language to embrace a more sociological account of language, they nevertheless retain the structural lens on their object of scrutiny. While the conception of language as a theoretical object shifts dramatically, the methodology used to study this object remains the same - as far as the linguistic level is concerned. Yet, this methodology is augmented by other methodologies coming from other disciplines - notably sociology -, when trying to understand "what is going on here (making use of language)".

Summing up, the unity breaks down (for certain strands of applied linguistics) with respect to a joint driving question. Yet, the object of interest (language) is as far as the structure is concerned seen and constructed alike, even though one is constructing it while the other is destructing the construct. Moreover, doing so presupposes a thorough understanding of this object and the framework it is stemming from. In addition, the "deconstruction" is usually demonstrated "locally" (e.g. demonstrating different patterns of phonetic variables - while other parts of speech are seen alike (Eckert 1989)), leaving the rest of the system firmly in place, something which also allows applied linguists to make use of methodology based in the structural account provided by general linguistics.

To me, there is one more aspect to be considered to bind applied linguistics back to "formal" linguistics, if one does not want to consider applied linguistics a mere "spin-off", sharing a point of origin but now taking its own path. I think the most important issue creating coherence between any two fields is whether developments in one field fuel the insights in the other field. (And it is usually this question, which is put to me when I am calling myself an applied linguist, yet not working in any of the established traditions therein.) While applied 
linguistics clearly draws on formal linguistics in its methodology, the "backflow" is less evident.

I think the most important contribution is the enrichment of our understanding of "language". Putting language in a social framework has significantly influenced at least some of the models used to model the language system, e.g. in taking up the issue of the flexibility and (context-dependent) variability of the language system (e.g. systemic functional linguistics, at the core of which stands a system of signification choices, a language producer has to make (Halliday 1994); optimality theory, which also models language through a choice function from the set of variants available (Prince, Smolensky 1993); statistical models of language acquisition, which no longer see the system as "pre-wired" but derive word categories through a statistical analysis of the input (Malouf, Carroll, Copestake, 2000)). Apart from influencing the philosophical foundation of our conceptions of language, applied linguistics also simply shares the task of explaining "how language works" (which includes "how discourse works", or "how language changes and is changed through its use") with general linguistics. Until the 70ies, general linguistics was thoroughly devoted to explaining language up to the sentence level. Only with the advent of text linguistics, linguistics started to move beyond. However, it soon became clear that texts are not organized according to the same principles as the levels "below" (Beaugrande, Dressler 1981; Beaugrande, 1995). Meaning (as constructed by "a reader") on the textual level is intimately intertwined with world knowledge and an inference system working on the text and the knowledge base (van de Velde, 1992). This also implies that "meaning" is to some degree something personal, an individual construction, which gives raise to the questions of "whose text", and "a meaning" or "meanings" attributed to "a text" if one does not want to stop with the individual. All these are questions, which were already prevalent for some time in literature studies, albeit there raised for literary texts, whereas linguistics is and was foremost concerned with the understanding of "everyday discourse", and texts. On an even more abstract level, texts (as linguistic units) can be viewed like words - being read, listened to, remembered by individual people, and taken up (in some aspects) by them. Thus, the question arises how are texts circulated, how do they built on each other, are set in opposition to each other, how do they develop, come and go. But these texts "carry" meaning; they are produced by particular people in particular circumstances for particular purposes. The coming and going, the dissemination of texts can thus no longer be separated from their social embedding, and the linguistic question becomes a social one, which ties in with questions of a long standing in sociology.

It is these levels above the sentence level, which is the focus of applied linguistics. When it comes to the text understanding of an individual, "the meaning" of particular utterances, there is an indeterminate area in which applied linguists and formal linguists work alongside, trying to understand the system, with formal linguists (or applied linguists - depending on the individuals' self definition) trying to flesh out the inference system(s) necessary to understand (or model) "what is going on". With the advance of knowledge engineering systems, more and more aspects of text understanding become prone to meticulous theories and tests by computer models (e.g. models of narratives, Polanyi 1998, or text extraction systems). Here, 
detailed studies of language use by applied linguists can help to shape the general architecture of inferencing systems and delineate the impact factors.

On the other hand, when it comes to the interplay of texts in a society, the way they influence the universe of discourse, i.e. our (textual) construction of the world, applied linguistics makes use of hermeneutics, leaving the world of general linguistics far behind. Here, applied linguistics can no longer "serve" general linguistics as input, here it provides its own account of "what language is" and "how language works" to shape and be shaped by our daily life.

Thus, it comes at no surprise, that applied linguistics is in need of its own theories and its own meta-theory, which models how applied linguistics approaches these questions.

Up to now, there are several models used to explain the interplay of language (use) or discourse and a particular (aspect of) social reality. Among others, Teun van Dijk (1989) strives to understand the permanence of racist prejudice (using cognitive models of the structure of a "prejudiced person" who is exposed to prejudiced discourse). Ruth Wodak (1998, 1990; Reisigl, Wodak 2000) explores the construction of national identities, discrimination in contemporary Austria (looking at the historical permanence of prejudiced discourse and their re-enactment in present-day mass media and politics) as well as decision processes within the EU. Norman Fairclough $(1989,1999)$ looks at how changes in discourse led to and were brought about by changing labour policies under conservative government in Great Britain. Most approaches combine sociological theories concerned with the very issue with (sociological) theories of a profoundly discursively structured social world (e.g. taking the ontological foundation from Foucault or Habermas/Austin, and enriching it with theories of the dynamics of discursive struggles for power by Gramsci or Althusser etc.) The driving question then becomes, which discursive formations (with which linguistic properties) can be discerned, and with which power claims and positions in the social field are they coupled. Adding a historical dimension, one can ask how this social-linguistic configuration shifted over time, and formulate a hypothesis about what linguistic and social elements helped to bring about this change - or helped to preserve the status quo.

What may seem so obvious when talking in abstract about the relationship of these theoretical approaches and the contribution of applied linguistics to linguistics in general, is nevertheless something which I personally often find hard to discern when confronted with a particular piece of supposedly applied linguistic research. Since the "field of application" is frequently some social problem (located in an institution or the public discourse or media discourse), the analysis of the conditions and consequences of a particular social practice may overshadow the theoretical linguistic consequences - and depending on the researcher, these may explicitly take second place to the attempt to contribute changing an existing (perceived) state of injustice. Thus, as a schizophrenic reader, I find myself intrigued by the sociological insights, while the linguist in me wonders "so what?".

I could stop the argument here, appealing to self-defined applied linguists (including myself) to be more explicit in their accounts of what they want to tell us about language. Yet, this would be short-sighted, ignoring the social field in which applied linguists have to work. While they are (sometimes) located in linguistic departments and thus constrained in their 
research and teaching by the institutional rules coming along with such a positioning, the world of publication is organized in a different way and puts different constraints on applied linguists. While there is a market out there for linguists and applied linguists, once larger social problems are addressed, every publisher (and author) will appreciate the much larger target audience of people being interested in sociological issues. Thus, especially large-scale studies of contemporary public discourse or an institutional discourse (e.g. doctor-patient communication) tend to be written up focusing on the problem under investigation instead of reflecting the linguistic methodology and consequences for the linguistic community. These points - if there remains time to do so between finishing up the final report and submitting the next grant proposal - tend to be presented in conference papers and smaller publications. In these forms, one frequently picks out only a small portion (e.g. a segment of an interview) of the data used for the whole project, and discusses e.g. the structural schema therein. Alternatively, one remains at the abstract level of the "struggle of discourses" and brings up a few exemplary cases to make the point. In either case, the resulting paper is targeted towards linguists and embraces tentatively a "narrow" conception of applied linguistics geared towards the language system in the framework of general linguists. That is, they either address how structural features of the text realize a particular meaning, or how the larger discursive system works. In both cases, the scope of the original large-scale research project is lost. Thus, I perceive the state of the art as an unsatisfying situation, in which applied linguistic research develops along some implicit principle which we seem to understand intuitively as members of the same community, but which is yet out of (conscious) grasp. In its explicit display on the scientific market, applied linguists serve two (and more) audiences, segmenting their work, loosing the implicit unity of their endeavour, and thus also loosing the place to reflect and reason on their implicit principles, which could be the basis for a stronger sense of unity.

Maybe one way to overcome the implied stagnation is to back away from theories of applied linguistics devoted to particular social systems, and to reason about theories of applied linguistic research on the meta-level. One such attempt to conceptualise applied linguistic research was recently developed by Ruth Wodak (2000).

In applied linguistic (discourse analytic) research, Wodak distinguishes between four levels of theoretical input being put to use in the analysis of a social/linguistic problem, which correspond to the different theoretical "objects" partaking in the analysed problem situation. On the "lowest" level are the texts with which the social world is re-enacted. Theories and methodologies of applied and general linguistics are brought to bear on the analysis of their structural features and corresponding signified meanings. On the next higher level, the analysis of various tokens is put into a framework of a theory of discourse, in which the tokens are brought into a relation with each other through concepts like intertextuality and interdiscursivity. In other words, these texts are not only text-tokens; they stand in particular relations to each other, which are spelled out in the form of a theory of discourse on this level. On the next higher level (the third level), middle range theories apply, which theorize various elements of the extra-linguistic situational context, i.e. theories on gender, theories on liberalism, theories on the mass media and their role in the public sphere, etc. Finally, a grand 
theory explicates the broader socio-political and historical context, within which the discursive phenomenon being studied occurs and gets its meaning.

Yet, Ruth Wodak's model is not only one presented to an applied linguistics audience analysing applied linguistic research methodology, but also to a (wider) discourse studies audience. As an applied linguist doing discourse studies, "applied linguistics" and "discourse studies" seem to become to be practically synonymous in the actual practice. Or, in a different perspective, applied linguists of a certain framework are indeed moving towards a new selfdefinition, namely discourse studies, in which the relation between the fields is more one between "equals" instead of "part-of-the-field", such that questions of legitimation like "what makes this proper linguistics/sociology/psychology" no longer arise.

This brings us back to the question of "academic marketing" - while "discourse studies" seem to have been successful to establish themselves on the publishing market, they are not established in the academia as far as the institutional structure (departments, institutes) are concerned. Thus, while someone might successfully publish discourse studies, she might not be able to transform this in permanent job.

In conclusion, there is no conclusion. The way the field (applied linguistics as well as discourse studies) is moving is not yet discernable. In the English speaking countries, applied linguistics will certainly continue to exist as "second language acquisition studies", but for the more anthropologically and sociologically oriented research it is not foreseeable, under which name and which institutional conditions discourse studies/applied linguistics will live on. Moreover, as far as Austria and maybe also part of Europe is concerned, shortage of budget puts pressure on "strange new subjects", which have no long standing and lobby (but the support of some highly visible researchers). On the other hand, the overall organization of higher-education is changing with the emergence of private universities, allowing the institutionalisation of completely new subjects and ideas.

\section{$2 \quad$ Applied linguistics and cultural studies - a joining of minds}

If we now turn to the question, what this heterogeneous field of applied linguistics has to offer to cultural studies, I think the answer is quite obvious. Like applied linguistics, cultural studies have been a newly emergent field in the circus of academia. Like applied linguistics, it is concerned with questions of the social configuration and social problems of our times. Both applied linguistics and cultural science strive to understand modernity, the conditions and problems of life in a heterogeneous complex society. The difference lays in the disciplinary origin, bringing along a different (but not incompatible) set of questions, a different perspective on what society is and from where to tackle the problems, as well as a different methodology.

As the name implies, cultural studies strives to look at "culture", the complex configuration of a historically shaped network of social relations, obligations, expectations, i.e. norms and traditions. Cultural studies strives to arrive at an understanding of the interplay of society and 
the individual, locating the individual in the social whole making use of theories of personal identity and identity formation in which humans are seen as historically and regionally contextualized symbol-generating and symbolically structured beings. Additionally, cultural science strives to understand the "social universe" as configuration of symbolically mediated constructions, a symbolic reality which is given by a symbolic universe through mass media, films etc. Thus, cultural science in a way tries to map out the space between individuals and society (as a symbolically structured field). Consequently, research contributing to our understanding of the relation between individual and society as a symbolically structured field can be understood as research in or contributing to cultural science.

In contrast, applied linguistics - as a field of linguistics also focused on symbol use, understanding and production - is concerned with the minute processes shaping concrete situations in institutions, the public realm, or the private sphere. Applied linguistics approaches the question of the conditions of modern being starting from an understanding of instances, of textual-discursive aspects, of tokens of living. In that it is indebted to the empirical bottom-up framework of general linguistics. Cultural studies on the other hand, relates back to more hermeneutic traditions.

Thus, I see applied linguistics (in its discursive manifestation) as the empirical other side of cultural studies. Cultural studies contribute more complex understandings to token situations studied in applied linguistics. And applied linguistics "grounds" cultural studies in concrete texts, demonstrates how the supposed meanings are enacted and recreated in concrete situations. In Wodak's metatheory of applied linguistic research, cultural science can be located at level three or four, that is depending on the very questions being raised, it either provides a mesotheory to make sense of some variable, or it contributes to the overarching framework, within which one makes sense of "what is going on here". Thus, cultural science can be and is used to make sense of questions being raised in some applied linguistic research; that is that kind of research, which tries to understand what is going on here beyond the immediate social situation. At the same time, this kind of research also contributes empirically grounded data (or rather interpretations) on symbolic practices.

In brief, applied linguistics and cultural studies are deeply intertwined. Not surprisingly then, both tend to "transgress" into each others (socially or institutionally defined) "territory", with applied linguists theorizing culture, and cultural scientists unpacking cultural texts using linguistic methods.

In the reminder of this article, I will present two examples of such a contribution of applied linguistics to cultural studies. The first will be a brief presentation of the changes of the meaning of "neutrality" in Austrian public discourse from 1955-1994. This study contributes to the empirical basis of changes in the perception of national identity and a feeling of life security in recent Austrian history. This perception - taken together with other elements could be the basis for the study of (aspects of) contemporary Austrian culture and selfunderstanding. 
The second study is a study on gender differences in group-work in Austrian high school physics classes. This study focuses on minute differences in participation and self-efficacy between boys and girls. Insofar as this enactment is taken as symptomatic of more prevalent gender differences created and re-created in Austrian schools and the Austrian society at large, this study contributes to our understanding of the re-creation of a gendered society, i.e. a gendered culture.

\section{$3 \quad$ A study of the discursive formation "Neutrality"}

In this study, an interdisciplinary team of linguists, sociologists and political scientists strove to understand the changes of the meaning of neutrality as a political concept in the second republic in Austria (Kovacs, Wodak, in press). Drawing on political speeches (Benke, Wodak, 1999), newspaper articles from that period, a recent TV discussion (Benke, Wodak 2001), poll data, expert interviews and focus groups on neutrality, we approached the meaning of neutrality from different angles, tracing its historical, political and discursive changes, and providing a rich picture of the complex meanings it acquired in different contexts (political, semi-public, mass-media, private) at the end of the analysed period (i.e. 1994).

Neutrality was seen not as a pre-given, legally defined concept - even though neutrality is imperative for Austria as we are neutral by law. Yet, throughout the second republic, the law was only a frame of reference for different interpretations, each of which has its own political agenda. (And even the law was at times set aside, when the state's antagonistic interests were deemed more significant.) Thus, for that period we saw neutrality as an important political concept, a place of discursive struggle for the power of interpretation, and as far as party politics was concerned for the power to make ones vision of the world come to be the unquestioned rule.

In my own contributions as a linguist, I analysed the verbal context of the occurrences of the lexeme neutrality (alongside a number of other aspects). Thus, I could show how in parallel to the political changes and instrumentalization of neutrality, the thematic context shifted from one, in which neutrality was mentioned as part of a "story of the (national) past", to an explicitly political context, in which neutrality was praised for enabling the state to play a mediating role in foreign politics. Alongside, I could demonstrate the operation of a stepwise metaphorization process, which I interpret as the linguistic reflection of the slow incorporation of "neutrality" into a complex framework of Austrian national identity.

In more detail, in the presidential speeches between 1974-1976, neutrality is presented as something that helped us (or requires us) to do something or reach a certain position. Thus "tasks fell to us because of neutrality", "Austria received meaning through neutrality" etc. On a semantic level, neutrality is often some instrument (expressed by a prepositional phrase) or a patient of some process that is not always one looked upon favourably.

In the following years, neutrality moves from the patient and instrument role to the agent position. Instead of "we were doing something/being forced to do something because of 
neutrality" it is now neutrality, which does something for us. Thus "neutrality gave us important tasks". The expression of the mediating function of neutrality is now delegated to the verb, which is often a transfer verb (give, mediate etc.) providing an argument slot for what is gained by neutrality. Thus, the instrument-relation between "us", i.e. the Austrian state, and neutrality is now expressed through a more complex predicate which offers enough argument slots and which sets up a three-way relation between a giver, a beneficiary and a transfer object. This change goes together with a positive re-evaluation of neutrality; at this point negative connotations do no longer appear in the immediate context.

Next, this complex expression (neutrality helped us to gain something) is shortened to the simple statement "Neutrality is helpful to us." Thus, the complex predicate is eradicated, the transfer process generalized and abstracted over as "help". Moreover, statements like these can be seen as a reflection on how much a matter of course the "helpfulness" of neutrality had become at that time - the speaker(s) did no longer see any need to argue their case, they could be sure that the audience would share their appreciation.

As the final step in this process of grammatical metaphorization, neutrality no longer appears as an explicit "other", which we (the Austrian state) stand in some relation to. In a statement like "our politics of neutrality is highly appreciated [by other countries]", our relation to neutrality is packed in a single nominal phrase. The relation to "us" is signified by the possessive pronoun, which is in itself an indication of the matter-of-course nature of this relation. At this point, our relation to neutrality is or was no longer anything even to address.

This sums up the processes until about 1988, when neutrality became a disputed issue as Austria was striving to enter the EU. At that point (with the iron curtain still in place) it was not clear whether Austria could enter the EU and retain its neutrality. Consequently, neutrality became "unpacked" again, although now against a back-drop of a widely shared consensus that "it was a good thing", and that it is "ours". Thus, we find more heterogeneous references to neutrality in the speeches, with neutrality appearing in a nominalization, being the actor, and becoming an object of reflection (i.e. a patient) "We consider the content and future of our neutrality".

In this case, the contribution of applied linguistics lays in providing a detailed empirically grounded and argued account of the meanings of neutrality at different times. Doing so, I made use of various methodological and theoretical concepts, thus also demonstrating their applicability and usefulness in discerning particular meanings. I demonstrated that there existed indeed different uses and presentations of neutrality over some time period. In a second step, these different uses can be mapped alongside the different political developments and situations, laying out an existing concurrency. This in turn gives credence to the complex models of discursive change, and struggles for power (hegemony) taking place in and through discourse. What cannot be done is to provide a stringent account of causal relations between language/discourse and the political momentary landscape (with regards to this issue).

Thus, this research supports and is supported by a particular perspective on language and the function of discourse in the public sphere. It shows how the abstract models of the (mutual) 
influence can be grounded in particular texts, grounding our impressions and hypotheses about some political change in concrete situations providing an empirical basis for our social/political/cultural theories.

On the linguistic side, this research demonstrates the usefulness of the concept of grammatical metaphorization (Halliday, 1994) for our understanding of language and language change. In addition it strongly supports Wittgensteinian conceptions of conceptual meaning, with meaning provided by the web of relations a concept is embedded in. The very progression of the concept of neutrality through different states could be taken as the starting point for a hypothesis about operating verbal and conceptual abstraction processes in the framework of cognitive linguistics.

\section{$4 \quad$ A study on gender differences in small group work in physics classes}

In this study, my colleague Helga Stadler, a physics teacher and educational researcher, and myself were interested to investigate girls' and boys' self-positioning in small group work in physics classes (Stadler, Benke, Duit, 1999; Stadler, Benke, Duit, 2001). One of the results of the TIMSS study (third international mathematics and science study) for Austria was, that in Austria there exists a significant gender difference in achievement in physics at the high school exit level. Taken together with frequently reported differences in interest in physics, we were interested in which way gender (gendered strategies) would manifest themselves in physics classrooms. ${ }^{1}$

As an applied linguist, I see instruction foremost as a symbolic activity. A person (the teacher) talks about something, structures a domain according to some semantic/conceptual principles, and tries to be understood. The students in turn are intended to learn the "language game", to accommodate the subjects' discourse, they learn to talk about particular issues and concepts in a particular way, tying one topic to another. Likewise, in group-work, they are supposed to talk science with each other to enact a particular language game, and reason or argue with the principles of this discourse.

In one part of our study, we decided to focus on two contrastive case studies of small groups working on some problem as part of a unit on the chaotic behaviour of a magnetic pendulum. Both groups we composed of a boy and two girls working together. In one case, the collaboration seemed to be a working together of equals; in the other case (that time a group working with a computer program) the boy was clearly dominating (or trying to dominate) the whole working process. Looking at the speech styles of the students, we found that in both

\footnotetext{
1 There is some controversy about research looking at gender differences from the outset, claiming that it is reifying gender, thus perpetuating a gendered perception of the world. As far as physics classes and courses are concerned, we take the stance that this is a world in which gendered perceptions are already prevalent (thus, we found strong gender stereotypes about interest in physics in a questionnaire study Benke, Stadler, 2002; indicative is also the low(er) percentage of women enrolling in physics at the university). Statistics tells us, that somehow gender (or something which is tied up with gender) makes a difference. Thus, we deem it sensible to actively search for differences in action, expectation and perception between girls and boys in this context.
} 
groups the boys and the girls used different strategies. Yet, the language game of the girls and the boys respectively were similar in both conditions. In the more equitable situation, the girls used additional strategies to assert themselves - strategies that were different from the assertive strategies of the boys.

Thus, we found that in both analysed groups, girls raised open-ended question, in which they voiced their confusion or not-understanding of something. Boys did not raise questions like that at all (and we have not come across such a question which situates oneself as admittedly not knowledgeable for boys in any other analysis of small group work). The boys would propose counter models, if they did not understand something, thus forcing a discussion on the issue. Moreover, they were likely to try to answer the "problems" of the girls, thus positioning themselves as the ones who have an answer, who are knowledgeable enough to be able to explain.

The boys' questions were frequently oriented towards the procedural aspects of the task, thus (if taken up) orienting the groups' focus and attention, as well as influencing the tasks' timing. (like: What do we have to do now? What is the next question? Did you do that?)

In terms of assertive strategies, mostly the boys used imperatives or proposed, "we do that". (Again, we find a focus on the procedural aspect of the task in this.) Girls rarely addressed the group or a group member in this way. In the equitable group, they were however quick to refute any suggestion they did not like. At the same time, the two girls were more prone to develop each other's themes than to take up something proposed by the boy. Thus, they achieved equity by refusing to be controlled.

Finally, in looking at the language boys and girls used, we found that girls frequently made use of everyday situations and metaphors in reasoning about physics, whereas boys tended to move within the system of physics, relating one physical concept to another one, without bringing in their everyday experiences or talking about themselves in a situation (like: the labile equilibrium is like when I am standing on top of a staircase).

In terms of education, there is a clear message to be told. We find that girls and boys make use of different speech styles as physics learners. Within the traditional classroom setting, one style (the boys') will frequently be more valued. Girls are willing to demonstrate lack of understanding; boys show themselves knowledgeable taking the explaining role. Girls talk about physics by talking about their lifes and the real world in everyday language. Boys "talk science".

Against an educational philosophy which values both the appreciation of the structure of a scientific domain as well as the appreciation of how the concepts are anchored and applied to the "real world", it is clear that both girls and boys have something valuable to learn from each other, and that no strategy is in itself superior. Thus, instruction should offer places for both, and demonstrate appreciation of both.

As for applied linguistics, the contribution made to general linguistics is no less complex as in the other case, even though it may seem more forthright with this research being concerned 
not with an abstract textual universe, but individual people making use of language. In that respect, this research can be seen as research on the language faculty on the pragmatic level, extending the formal approaches of syntax and semantics. It also addresses the question of how world knowledge is being built up, how it relates to discourse, that is how people enter and accommodate a particular discourse. Moreover, this research addresses the question of how people position themselves in the world through and by language. It informs us on operating (pragmatic and socio-linguistic) rules and their variations.

Thus again, we find that this kind of research extends the "meaning" of language, addressing questions that are outside the scope of general linguistics, yet important for our understanding of "how language works". In particular, it informs our understanding of the function(s) of language, which in turn can tell us something about the origins of the language faculty, as well as inform our theories of first language acquisition as something starting with pragmatics (e.g. Tomasello, 1997).

In brief, in this research framework language is positioned between or mediates a social and a cognitive dimension akin to Vygotsky's theory of internationalisation of the social in the process of individuation. In this framework it often becomes insensible to raise questions like "is this linguistic or social", "is this cognitive or linguistic". And sometimes, it even becomes meaningless to ask, "is this cognitive or social". The division is one brought along by the disciplinary structure of our institutionalization of knowledge. Consequently, while I see more relations to "general linguistics" present in this kind of research (in contrast to the study presented above), it is at the same time also this study, in which the separation of the disciplines is more clearly breaking down, thus inviting criticism that one is not doing linguistics, but sociology or psychology or cognitive science or education or gender studies or.

\section{The relation to Cultural Science}

Considering the two described research projects, we find the applied linguistics of only these projects already to be quite distinct, addressing different levels of the complex individualsociety, locating language at different positions. Yet, I hypothesize, that as both projects can be located in this complex, both also contribute to and can make use of cultural science.

The contribution differs according to the implicit definition of language used in the study. In the first study presented above, we find data on how a concept changed over some time period in the public discourse. This finding can contribute to a deeper understanding of how symbolic formations dominate public discourse and taken together with the larger political context, it can be taken as a starting point to reflect on what brings about change of public discourse and (as in the case of neutrality in Austria) ultimately national identity.

The second study also addressed questions of identity, albeit now focused more on individuals enacting particular (gender) identities. Here, the findings contribute to our understanding of how gender is re/enacted in a particular context, which is frequently already perceived as gendered, at the same time as the gender distinctions are brought into situational existence, as students are encultured in a particular scientific community. 


\section{Conclusion}

After all this discussion on the near identity of the ultimate object of analysis of cultural studies and (a certain strand of) applied linguistics, I might conclude with a statement to the effect that we ought to overcome any possible differences and see ourselves as "from the same family". But I do not think that eventual unity (in some other possible universe), becoming one discipline with a shared ultimate object would ultimately lead to a (scientifically) more glorious future. On the contrary. Especially in recent years, walking on the fringe of applied linguistics, working together with teachers and teacher educators, I find myself again and again acting as an (applied) linguist, bringing along a set of assumptions, a regard for this symbolic field which is different than the one other people from other backgrounds bring along. Thinking about and studying language, its structure and variation, has deeply influenced my thinking about language, style and stylistic differences, the perception of discourse and argumentation. The differences in disciplinary origin turn into a constructive tension when meeting with openness of minds. And it is this tension of many different strands and influences from multiple disciplinary origins, which infuse applied linguistics and cultural studies with rich meanings. Yet, as scientifically stimulating as this can be, the (institutional) status of these (not so) new in-between and intensively interdisciplinary approaches to social science is still precarious.

\section{References}

Beaugrande, Robert Alain de (1995): A new Introduction to text and discourse. London.

Beaugrande, Robert-Alain de/Dressler, Wolfgang Ulrich (1981): Einführung in die Textlinguistik. Tübingen.

Benke, Gertraud/Wodak, Ruth (2001): "Neutrality versus Nato: The Analysis of a TVDiscussion on the Contemporary Function of Austria's Neutrality". In: Bischof, Guenter/ Pelinka, Anton/Wodak, Ruth (eds.): Neutrality in Austria. Contemporary Austrian Studies. Volume 9. New Brunswick, NJ: 37-68.

Benke, Gertraud/Wodak, Ruth (1999): "'We are no longer the sick child of Europe': An Investigation of the Usage (and Change) of the Term 'Neutrality' in the Presidential Speeches on the National Holiday (26 October) from 1974 to 1993". In: Wodak, Ruth/ Ludwig, Christoph (eds.): Challenges in a Changing World - Issues in critical discourse analysis. Wien: 101-126.

Benke, Gertraud/Wodak, Ruth (2001): "Fulfilling One's Duty? Memorizing what has not been". In: Lappin, Eleonore/Schneider, Bernhard (eds.): Die Lebendigkeit der Geschichte. (Dis-)Kontinuitäten in Diskursen über den Nationalsozialismus. St. Ingbert: 257-296.

Benke, Gertraud/Stadler, Helga (2002): "Interest, gender image and students' identity construction as physics learners". Paper presented at the conference of the national association for research in science teaching (NARST). New Orleans.

Clark, Herb H./Wilkes-Gibbs, Deanna (1992): "Referring as a Collaborative Process". In: Clark, Herb H. (ed.): Arenas of Language Use. Chicago: 107-143.

Coupland, Justine/Robinson, Jeffrey D./Coupland, Nikolas (1994): "Frame negotiation in doctor-elderly patient consultations". Discourse and Society 5, no. 1: 89-124. 
Crawford, Mary (1995): Talking Difference. On Gender and Language. London.

Eckert, Penelope (1989): "The whole woman: Sex and gender differences in variation". Language Variation and Change 2 (1989): 205 - 254.

Fairclough, Norman (1999): "Democracy and the public sphere in critical research on discourse". In: Wodak, Ruth/Ludwig, Christoph (eds.): Challenges in a Changing World Issues in critical discourse analysis. Wien: 63-86.

Fairclough, Norman (1991): Language and Power. London.

Fairclough, Norman/Wodak, Ruth (1997): "Critical Discourse Analysis". In: van Dijk, Teun A. (ed.): Discourse as social interaction. Discourse Studies. Vol. 2. London: 258-284.

Gumperz, John (1982):Discourse Strategies. Cambridge.

Halliday, M.A.K. (1994): An Introduction to Functional Grammar. London.

Klampfer, Sabine/Vollmann, Ralph/Dressler, Wolfgang U. (2000): "Zur Rolle interindividueller Variation im frühen Morphologieerwerb". Grazer Linguistische Studien 54 : 59-72.

Kovacs, Andras/Wodak, Ruth (eds.) (2003): NATO, Neutrality and National Identity: the case of Austria and Hungary. Wien.

Kress, Gunther/Leeuwen, Theo van (1996): Reading Images. The Grammar of Visual Design. New York.

Lalouschek, Johanna/Menz, Florian/Wodak, Ruth (1990): Alltag in der Ambulanz. Tübingen.

Malouf, Robert/Carroll, John/Copestake, Ann (2000): "Efficient feature structure operations without compilation". Natural Language Engineering 6 no.1: 29-46.

Matouschek, Bernd/Wodak, Ruth/Januschek, Franz (1995): "Notwendige Maßnahmen gegen Fremde?": Genese und Formen von rassistischen Diskursen der Differenz. Wien.

McKoon, Gail/Ratcliff, Roger (1992): "Inference During Reading." Psychological Review 99 no.3: 440-466.

Ochs, Elinor/Gonzales, Patrick/Jacoby, Sally (1993): "'When I come down I'm in the domain state': Grammar and Graphic Representations in the Interpretive Activity of Physicists". L.A.: TESL \& Applied Linguistics UCLA, (draft).

Pfeiffer, Oskar/Strouhal, Ernst/Wodak, Ruth (1987): Recht auf Sprache. Verstehen und Verständlichkeit von Gesetzen. Wien.

Polanyi, Livia (1998): "A formal model of the structure of discourse". Journal of Pragmatics 12: 601-638.

Prince, Alan/Smolensky, Paul (1993): "Optimality Theory: Constraint Interaction in Generative Grammar. RuCCS Technical Report 2". Piscataway, NJ: Rutgers Center for Cognitive Science, Rutgers University, and Boulder, CO: Department of Computer Science, University of Colorado.

Reisigl, Martin/Wodak, Ruth (2000): Discourse and Discrimination. London.

Sacks, Harvey (ed.) (1995): Lectures on Conversation. Vol I \& II. Cambridge, MA.

Saussure, Ferdinand de (1967): Grundlagen der allgemeinen Sprachwissenschaft. Berlin.

Schegloff, Emanuel A. (1991): "Conversation Analysis and Socially Shared Cognition". In:

Renick, L. B./Levine, J. M./Teasley, S. D. (eds.): Perspectives on Socially Shared Cognition. Washington, D.C.: 50-171.

Schiffrin, Deborah (1987): Discourse markers. Cambridge. 
Sperber, Dan/Wilson, Deidre (1995): Relevance. Communication \& Cognition. 2nd ed. Oxford.

Stadler, Helga/Benke, Gertraud/Duit, Reinders (1999): "How do boys and girls use language in physics classes?". In: Research in Science Education. Past, Present, and Future. Proceedings of the Second International Conference of the European Science Education Research Association (E.S.E.R.A.). Kiel: 531-533.

Stadler, Helga/Benke, Gertraud/Duit, Reinders (2001): "Gemeinsam oder getrennt? Eine Videostudie zum Verhalten von Mädchen und Buben bei Gruppenarbeiten im Physikunterricht". In: von Aufschnaiter, Stefan/Welzel, Manuela (eds.): Nutzung von Videodaten zur Untersuchung von Lehr-Lern-Prozessen. Münster: 203-218.

Tannen, Deborah (1989): Talking voices. Repetition, dialogue, and imagery in conversational discourse. Cambridge.

Tomasello, Michael (1997): "The pragmatics of word learning". Japanese Journal of Cognitive Science 4: 59-74.

Van Dijk, Teun A. (1989): "Mediating racism. The role of the media in the reproduction of racism". In: Wodak, Ruth (ed.): Language, Power and Ideology. Studies in Political Discourse. Amersterdam, Phil: 199-226.

Velde, Roger G. van de (1992): Text and Thinking. On Some Roles of Thinking in Text Interpretation. Berlin.

Wilkinson, Sue/Kitzinger, Celia (eds.) (1995): Feminism and Discourse. Psychological Perspectives. London.

Wodak, Ruth (2000): "Does Sociolinguistics need Social Theory? New Perspectives in Critical Discourse Analysis. Keynote Address". Paper presented at the Sociolinguistic Symposium 11, April 2000, Bristol: 27-29.

Wodak, Ruth (2001): Theorie und Praxis Interdisziplinärer Forschung und ihrer Anwendungen: EU-Diskurse zur Beschäftigungspolitik. Passau.

Wodak, Ruth/Andraschko, Elisabeth/Lalouschek, Johanna/Schrodt, Heidi (1991): "Schulpartnerschaft zwischen Gesetz und Wirklichkeit". Wien: Institut für Sprachwissenschaft: 40-123.

Wodak, Ruth/Novak, Peter/Pelikan, Johanna/Gruber, Helmut/Cillia, Rudolf de/Mitten, Richard (1990): "Wir sind alle unschuldige Täter". Diskurshistorische Studie zum Nachkriegsantisemitismus. Frankfurt am Main.

Wodak, Ruth/Cillia, Rudolf de/Reisigl, Martin/Liebhart, Karin/Hofstätter, Klaus/Kargl, Maria (1998): Zur diskursiven Konstruktion nationaler Identität. Frankfurt am Main. 